\title{
Language over time
}

\section{Some old and new uses of OKAY in American English}

\author{
Elizabeth Couper-Kuhlen \\ University of Helsinki
}

This paper demonstrates how the tools of Interactional Linguistics can be applied to the study of change in language use. It examines the particle OKAY as used in everyday American English interaction at two different points in time, the 1960 ond the 1990 os/early 20oos. The focus is on the remarkable increase of OKAY as a response in epistemically driven sequences. Three uses of epistemic OKAY are identified in the newer data, one of which is unattested in the older data: OKAY in response to information that has no implications for the recipient's agenda or expressed beliefs. This novel use of OKAY appears in the newer data where $\mathrm{OH}$ would have occurred earlier, although $\mathrm{OH}$ is still attested with displays of affect such as surprise and empathy. The study concludes by arguing for an examination of 'possibility spaces', the set of options for filling a given sequential slot in conversational structure, at different points in time as a means for identifying changes in language use.

Keywords: OKAY, epistemics, response, informing, correction, longitudinal

\section{Introduction}

Since the inception of Interactional Linguistics (Ochs, Schegloff, \& Thompson, Eds., 1996; Couper-Kuhlen \& Selting, Eds., 2001), its proponents have been concerned to describe language as a resource for social interaction using audio and video recordings from a wide range of social encounters for empirical analysis. But little attention has been paid to when these social encounters take place: Instead they are treated as occurring in an undifferentiated and indefinitely expandable "Now". Yet time does go on, and the conversational recordings studied, for example, by the first generation of conversation analysts (Sacks, Schegloff, \& Jefferson 1974; Sacks 1992; Lerner, Ed., 2004) are beginning to show their age. 
This is evidenced not only when participants refer to events of over sixty years ago (witness the Robert Kennedy assassination) as having just happened, but also when they use language in ways that sound dated today (witness expressions such as 'call collect', 'bone shoes', or 'nickel bag'). Nevertheless, the fact that we have access to these older recordings is a treasure not to be underestimated: They allow us, with the tools of Interactional Linguistics, to compare talk-in-interaction from then with talk-in-interaction now and explore how conversational language use has changed in the meantime. The present study does just this. However, rather than focusing on lexical expressions, it explores how linguistic practices for implementing social actions have evolved over the course of a generation. ${ }^{1}$

\subsection{The present study: Conception and development}

The current study grew out of a cross-linguistic project organized by the Helsinki Center of Excellence on Intersubjectivity and the Leipniz Institute for the German Language that set out to document the range of interactional uses of the particle OKAY $^{2}$ across thirteen different languages (Betz, Deppermann, Mondada \& Sorjonen, Eds., In press). One of these was American English, where the word OKAY is thought to have originated (Metcalf 2010). A first investigation of American English OKAY within the cross-linguistic project focused on the prosody and phonetics of the particle in its various uses (Couper-Kuhlen, In press-a). Since one of the aims of the cross-linguistic project was to obtain as comprehensive a picture as possible, the American English OKAY collection was initially built to encompass approximately eight hours of everyday talk-in-interaction and included exemplars of OKAY from both early conversational data, recorded during the 1960s, as well as from more recent conversations, recorded during the 1990 s and early 200os. The two sub-collections, referred to as the "older" and the "newer" data, were analyzed separately, permitting a first glimpse of changes in the use of OKAY over time.

For the current study the data set from the first investigation of OKAY was expanded from eight to more than 14 hours of conversational talk. It now includes audio recordings of two-party telephone calls and video recordings of multi-party

1. In this respect the present study follows in the footsteps of Clayman \& Heritage (2002), who investigate the ways in which journalists' questioning of U.S. presidents has changed over time. 2. 'OKAY' in all capitals refers generically to the myriad phonetic and prosodic variations of the word on specific occasions. 
face-to-face interaction with equal amounts of "older" data ${ }^{3}$ and "newer" data ${ }^{4}$ as measured in minutes of recording. The two sub-collections are comparable in that both contain recordings of family and friends talking on the telephone or chatting in informal settings: Little else is going on in these situations than talk. There are no institutionally prescribed allocations of turns or topics of talk; the occasions for talking are equally varied in the two sub-collections. The two sub-collections thus embody mundane conversation at its best.

All tokens of the particle OKAY in the conversations were extracted in their context of occurrence. Included were freestanding OKAYs, i.e., cases in which the particle builds a turn-constructional unit of its own, as well as OKAY combinations, i.e., cases in which the particle co-occurs with another particle as part of a prosodically cohesive unit (e.g., oh OKAY, yeah OKAY). The frequency of OKAY tokens in the two sub-collections turned out to be roughly the same (see Table 1):

Table 1. Frequency of the particle OKAY in the sub-collections

\begin{tabular}{lcc}
\hline Sub-collections & Sum of recording durations & Number of OKAY tokens \\
\hline Older data & $25,308 \mathrm{sec} .=421.8 \mathrm{~min}$. & 277 \\
Newer data & $25,339 \mathrm{sec} .=422.3 \mathrm{~min}$. & 273 \\
\hline
\end{tabular}

\subsection{Uses of OKAY in the older and newer data}

Once the sub-collections had been set up, each exemplar of the particle OKAY was examined in its context of occurrence to determine how it was being used, that is, to establish its position in conversational structure and, where relevant, its composition as a phonetic-prosodic object. The ultimate goal was to determine what action each OKAY token was implementing in the given conversational environment. In the following we survey the uses of OKAY identified in the two subcollections.

3. The "older" sub-collection from the 1960 included the multi-party video recordings known as Chicken Dinner, Chinese Dinner, Stew Dinner, and Virginia, as well as the audio recordings of all transcribed Newport Beach and Santa Barbara Ladies telephone calls plus assorted other two-party telephone calls (Debby \& Shelley, Geri \& Shirley, Hyla \& Rich, Hyla II, Joyce \& Stan, Kamunsky 1-3, Linda \& Jerry, Madeline, and Two girls).

4. The "newer" sub-collection from the 1990 s and early 2000 included the multi-party video recordings known as Americans (Rossi Corpus of English), Before bed and Camp Reunion 1 \& 2 (Arizona corpus), Farmhouse and Game Night as well as 17 two-party telephone calls (8 selected randomly from the Call Friend collection and 8 from the Call Home collection plus 1 from the Santa Barbara Corpus of Spoken American English). 


\subsubsection{OKAY in the older data}

There were five recurrent uses of the particle OKAY in the older data (ordered here from most frequent to least frequent). Most frequent was the use of OKAY in deontic sequences, that is, in those centered around a request/instruction, a proposal/suggestion, or an offer/invitation (Stevanovic \& Peräkylä 2012; Drew 2012; Couper-Kuhlen 2014). In these cases, OKAY appears in second position, as, for instance, in the following exchange, where it is used to acquiesce to a request: ${ }^{5}$

OKAY in the second position of a deontic sequence

(1) “Whole town" (Newport Beach 18, 295.78) [Older data] ((Fran is planning to visit Ted at the beach; he has just given her instructions on how to get there by car.))

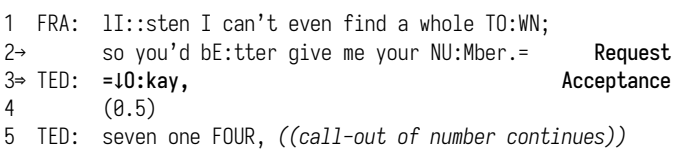

Alternatively, OKAY can appear in the third position of a deontic sequence, where the original instigator of a request/proposal/offer acknowledges its acceptance or rejection by the interlocutor (Thompson, Fox, \& Couper-Kuhlen 2015: 224):

OKAY in the third position of a deontic sequence

(2) “Richard's for lunch" (Newport Beach 28, 2539.12) [Older data] ((Lottie has been offering to take Emma shopping or to the hairdresser's but Emma has declined both times.))

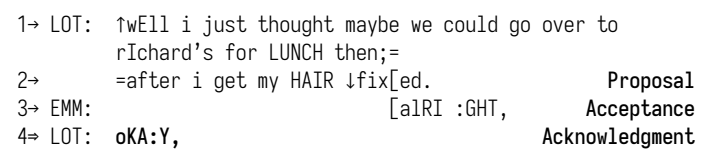

In addition to figuring in deontic sequences, OKAY in the older data also appears in between sequences in a 'continuative' function to transition to 'next-positioned matters' (Beach 1993). In this use the particle prefigures a fuller turn by the speaker or the interlocutor involving a shift of topic or activity. For instance:

5. This and all subsequent data extracts have been transcribed according to the GAT2 conventions (Selting et al. 2009; Couper-Kuhlen \& Barth-Weingarten 2011). 
OKAY as a marker of transition to a new topic or activity

(3) "Reason I'm calling" (Kamunsky 3, 90.52) [Older data] ((Alan has called Maryanne to invite her to a party, but she preempts first topic by announcing news about a mutual friend, Tony. In this extract, the topic of Tony is currently being closed down.))

1 ALA: that was what i TOLD him;

$2 \rightarrow \quad$ it's $<<$ rhythmic $>$ aBOUT TI:ME. $>=$

$\rightarrow \quad=y o u \mathrm{kno}[\mathrm{W}$.

$3 \rightarrow$ MRY:

$4 \Rightarrow$ ALA:

5

$[\mathrm{GO}::::::[::::[\mathrm{D}]$.

$\left[{ }^{\circ} \mathrm{hhh}[\mathrm{Ok}]\right.$ ay;

well the REAson i'm calling;=

=there IS a reason behind my mAdness.

((turn continues))

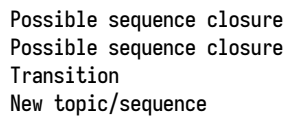

Equally as frequent as transitional OKAY in the older data is the use of the particle OKAY in pre-closings to open up the closing of a telephone conversation (Schegloff \& Sacks 1973):

\section{OKAY in pre-closings}

(4) "Okay sweetie" (Newport Beach 16, 354.04) [Older data]

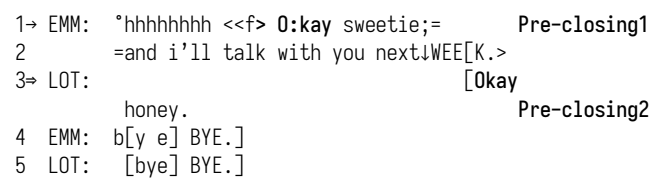

Much less frequent than pre-closing OKAY in the older data is its use in epistemic sequences, that is, in those centered around an informing, announcement, or telling (Terasaki 2004; Maynard 1997; Heritage 2012b). In such cases OKAY can appear in second position, where it acknowledges a prior informing:

OKAY in the second position of an epistemic sequence

(5) "Knives" (Chinese Dinner, 17:13) [Older data]

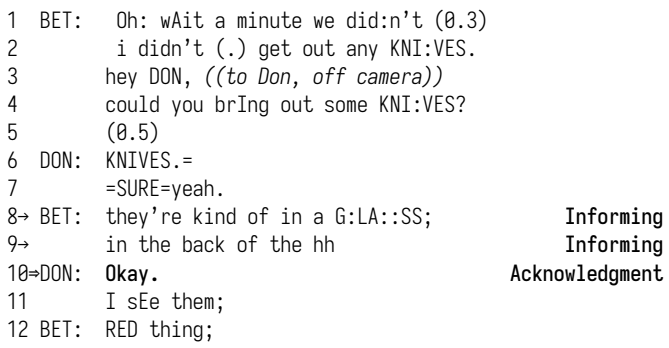

Alternatively, OKAY in the older data can appear in the third position of an epistemic sequence, where it acknowledges an informing that has been elicited through a prior query: 
OKAY in the third position of an epistemic sequence

(6) "Hear you fine" (Joyce \& Stan, 0.55) [Older data]

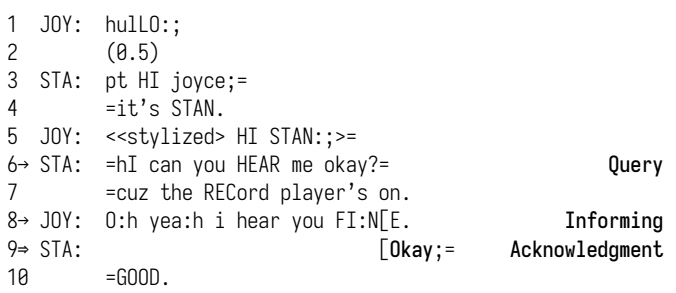

Finally, OKAY in the older data is on occasion encountered in a tag position, attached to the end of a request/proposal/offer, where it solicits uptake:

OKAY as a tag

(7) "Get home early" (Linda \& Jerry, 53.85) [Older data]

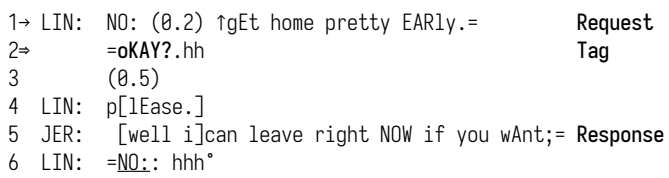

\subsubsection{OKAY in the newer data}

Most of the uses of OKAY documented in the older data were also observed in the newer data. However, one new use appeared: OKAY as a continuer (Schegloff 1982), where it occurs at a point of syntactic, intonational, and/or pragmatic incompletion in the interlocutor's turn, inviting the other to go on:

\section{OKAY as a continuer}

(8) “Moving" ( $\mathrm{CH} 4248,175.77)$ [Newer data]

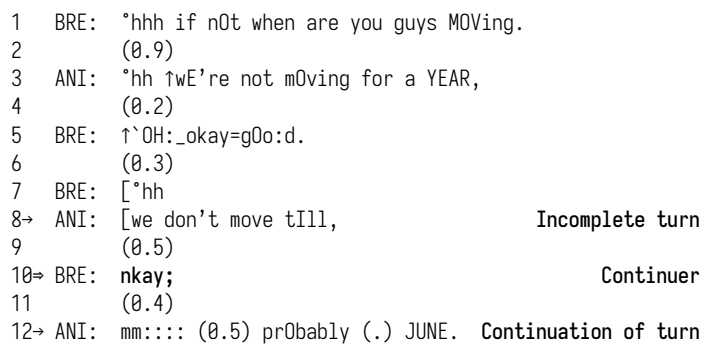


Table 2 summarizes the recurrent uses of OKAY in the older and newer data and their frequencies. ${ }^{6}$

Table 2. Recurrent uses of the particle OKAY in the older and newer data (with frequencies)

\begin{tabular}{lcccccccc}
\hline & Deontic & Transitional & $\begin{array}{c}\text { Pre- } \\
\text { closing }\end{array}$ & Epistemic & Tag & Continuer & Other & Total \\
\hline Older & 122 & 59 & 59 & 19 & 12 & - & 6 & 277 \\
data & $(44 \%)$ & $(21 \%)$ & $(21 \%)$ & $(7 \%)$ & $(4 \%)$ & & $(2 \%)$ & \\
Newer & 67 & 32 & - & 140 & 8 & 11 & 15 & 273 \\
data & $(25 \%)$ & $(12 \%)$ & & $(51 \%)$ & $(3 \%)$ & $(4 \%)$ & $(5 \%)$ & \\
\hline
\end{tabular}

If we now compare the uses and frequencies of OKAY in the two subcollections, some interesting findings emerge. First, the distribution of OKAY has broadened in the newer data: It is now attested recurrently as a Continuer, although this is offset by the absence of Pre-closing OKAY in the newer data. This absence is presumably due to the fact that none of the telephone calls transcribed in the 1990-2000 sub-collection included the closing section of the conversation. Second, and more importantly, the frequency of OKAY in epistemic contexts has grown exponentially in the newer data: This use now accounts for more than half of all OKAY tokens in total. Epistemic OKAY in the newer data is more than twice as frequent as deontic OKAY, which in the older data accounted for almost half of the OKAY tokens in total. How can this be?

One explanation for the fewer instances of deontic OKAY in the newer data compared to the older data may have to do with the composition of the data base. Many of the telephone calls in the older Newport Beach and Santa Barbara Ladies collections, for instance, were made 'for cause', that is, to ask for a favor, arrange a get-together, or invite someone to a party - in other words, they contained numerous deontic sequences. But the telephone calls in the newer Call Friend and Call Home collections were 'engineered' to gather speech samples: Participants agreed to make long-distance calls for free to friends and relatives and they were told they could talk about whatever they wanted. For this reason, there may be fewer deontic sequences than epistemic ones in the newer data.

But informing and telling sequences are by no means absent in the older data. Thus, there must be some deeper explanation for the remarkable increase in the

6. The 'Other' category in the older data set includes 6 tokens of OKAY used to introduce Reported speech. In the newer data set it includes 11 tokens of OKAY introducing Reported speech and 4 tokens of turn-internal OKAY marking a concessive relation. 
number of OKAY tokens appearing in epistemic sequences in the newer data. The next section explores what is behind the rise of epistemic OKAY.

\section{The rise of epistemic OKAY}

Let us first consider what epistemic sequences look like in the older data.

\subsection{Epistemic sequences in the older data}

Much as Heritage's early work has shown, following simple informings it is the token $\mathrm{OH}$ that is used to receipt information as something the speaker did not know before and to mark it as having brought about a change of state (1984:300). Here is a case from the older data: (a single arrow marks the informing and a double arrow the response, which is also bolded)

(9) “Coming down this weekend" (Newport Beach 14, 358.30) [Older data] ((Emma is telling her sister Lottie about an upcoming visit from her daughter and family.))

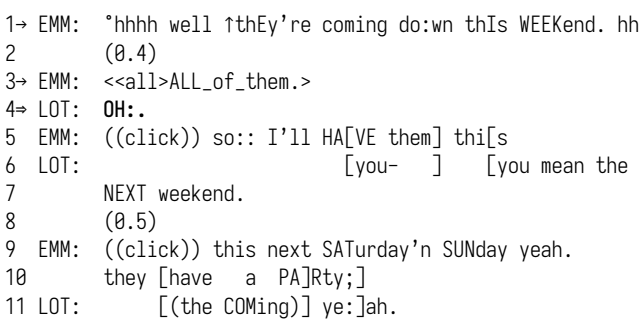

Likewise, it is typically $\mathrm{OH}$ that is found in response to question-elicited informings in the older data. Here are three instances, also noted by Heritage (1984:310): (single arrows mark the question and the answer, which is bolded; double arrows mark the response)

(10) "Freedland" (Hyla II, 678.58) [Older data]

((Hyla has just told her friend Nancy that she recently tried to call her exboyfriend long-distance but when he answered the phone, she hung up.))

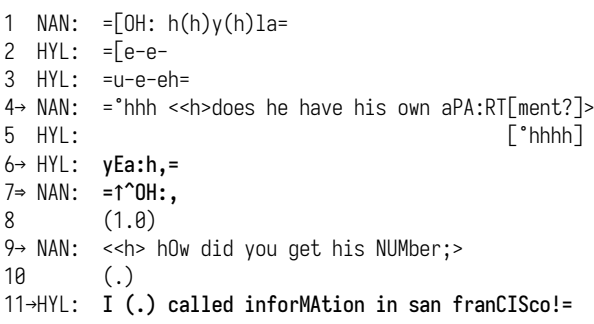




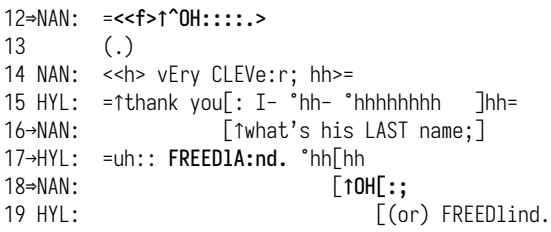

Finally, it is also $\mathrm{OH}$ that we find as a response after repairs in other-initiated repair sequences in the older data (see also Heritage 1984:316):

(11) "Acne" (Hyla II, 86.224) [Older data]

[Nancy is telling her friend Hyla about a recent trip to the skin doctor.]

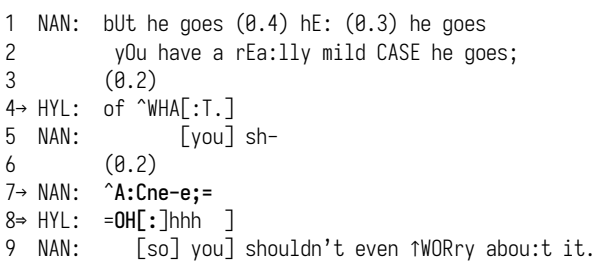

In sum, it is predominantly the particle $\mathrm{OH}$ that is used following simple informings, question-elicited informings, and other-initiated repairs in the older data. In such cases $\mathrm{OH}$ receipts the information given in the prior turn as having led to a change of state from not-knowing [K-] to now-knowing [K+] (Heritage 2012-a) and implies that the sequence can now be closed.

Yet there are isolated instances of epistemic sequences in the older data where it is the particle OKAY rather than $\mathrm{OH}$ that appears as a response to an informing. These cases are particularly instructive for how OKAY has developed in the meantime. Consider, for instance, the following sequence from the older data:

(12) "What are you gonna wear" (HGII, 1136.840) [Older data] ((Hyla has invited Nancy to the theater that evening to celebrate her birth-

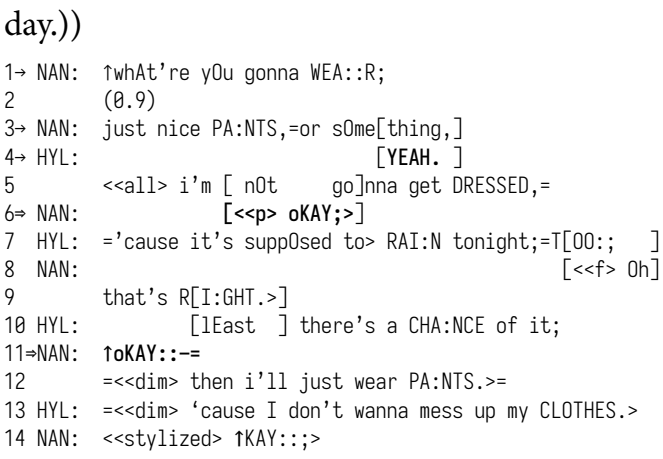

In line 1 Nancy orients to Hyla as the organizer of the evening's program by asking what she intends to wear, providing a candidate answer herself after a pause: 
just nice pants or something (line 3). Hyla confirms this with yeah - an informing which Nancy, in overlap with Hyla's turn extension, now acknowledges with OKAY in line 6 and, following Hyla's account for not wanting to dress up (lines 7 \& 10), with a second OKAY in line $11 .{ }^{7}$ But why does Nancy use OKAY and not OH to respond to Hyla's informing? How is this sequence different from the one we saw in Extract (10), where Nancy's query does he have his own apartment? (line 4) receives a yeah response (line 6) which is acknowledged with $\mathrm{OH}$ (line 7)?

The answer appears to lie in the import of the question being asked, that is, in whether the information it is eliciting is consequential for that speaker's agenda or not. While it is not consequential for Nancy to know whether Hyla's ex-boyfriend has his own apartment, it is on the contrary highly relevant for Nancy to know what Hyla will wear to the theater that evening, because this has consequences for what Nancy herself should wear. Nancy goes on to draw those implications when she says a split second later then I'll just wear pants (line 12).

Other instances of simple OKAY in epistemic sequences in the older data are like the one in Extract (12): The tokens are used to acknowledge information that is consequential for the speaker's future behavior in one way or another, often information that they themselves have elicited.

But there are also isolated cases of a second type of epistemic OKAY in the older data, namely, one used to acknowledge a correction or counter-informing. This type of OKAY may appear together with $\mathrm{OH}$, as in:

(13) “One guy I wanna call" (Chicken Dinner, 14:42) [Older data]

((Vivian and her friends have been talking about a blizzard on the East coast, which contrasts with the warm weather they are having on the West coast.

Shane is Vivian's partner.))

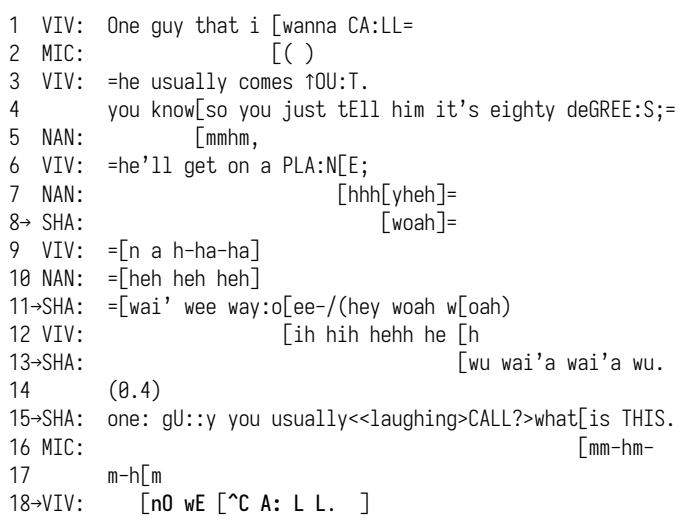

7. These two OKAYs (in lines 6 and 11) - based on their position and (prosodic) composition are clearly responding to Hyla's informing about what she will wear, while the OKAY in line 14, with its stylized 'sung' prosody, functions as a transition to new matters (Beach 1993). 


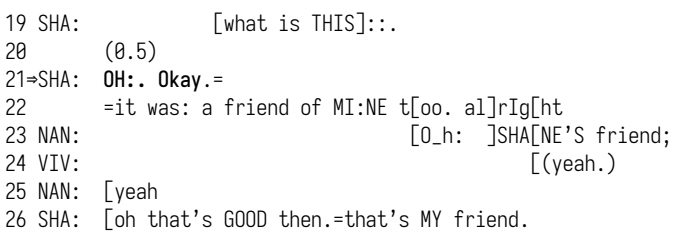

Shane, as Vivian's partner, teasingly plays the jealous lover and challenges her on claiming that there is a guy she usually calls (lines $8,11,13 \& 15$ ), but Vivian clarifies that she calls this person together with Shane: $n O w E C A L L$ (line 18). It is this correction that Shane acknowledges after a brief pause with $\mathrm{OH}$ :. Okay (line 21). Here too the OKAY is indexing the consequentiality of the informing for Shane, yet its implications concern not his future behavior but rather his understanding of the situation: As he goes on to say, it was a friend of MINE too. alrIght (line 22). That is, any grounds for jealousy have now been eradicated. Together with $\mathrm{OH}$, marking that Vivian's correction has led to a change-of-state in Shane's knowledge, this OKAY acknowledges the information as having brought about a revised understanding of the situation in question.

To summarize: In the older data it is predominantly $\mathrm{OH}$ that is found as a response in the second and third positions of epistemically driven sequences, including those built around simple informings, question-elicited informings, and other-initiated repairs. On occasion (19 times in seven hours of conversation), it is OKAY that crops up in such sequences; these are invariably cases in which the information that has been conveyed, often on solicitation, (i) is consequential for the speaker's agenda, or (ii) leads to the speaker's revised understanding of the situation in question. In the latter case $\mathrm{OH}$ often co-occurs with OKAY.

\subsection{Epistemic OKAY in the newer data}

In contrast to the relatively few tokens of epistemic OKAY in the older data, there are 140 tokens of OKAY in second and third positions of epistemically driven sequences in the newer data. In close to three-fourths of these cases, OKAY is used as in Extracts (12) and (13) from the older data. In the following we examine these newer epistemic OKAY tokens more closely.

\subsubsection{Consequential OKAY}

Nearly half of the epistemic OKAYs in the newer data are used, as in Extract (12), to acknowledge information that has some consequence for the speaker's agenda or future behavior. Here is a sampling of sequences where the informing (single arrow) has been volunteered and is receipted with OKAY (double arrow, bolded): 
(14) "Hang on just a sec" (Hey Cutie Pie, 480.200) [Newer data] ((While Jill is visiting a friend Jill2, she has called her boyfriend Jeff long distance.))

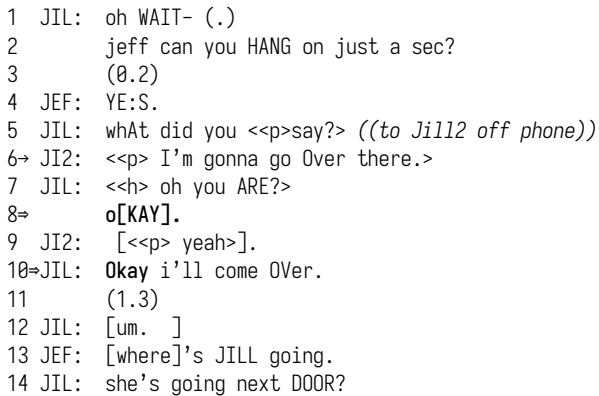

(15) "Very shortly" (Game Night, 267.685) [Newer data] ((Pam has interrupted the board game she is hosting and gone into the kitchen to answer a phone call from her sister Jill. As she is talking on the phone, she looks in from the adjoining room and addresses line 1 to the other players.))

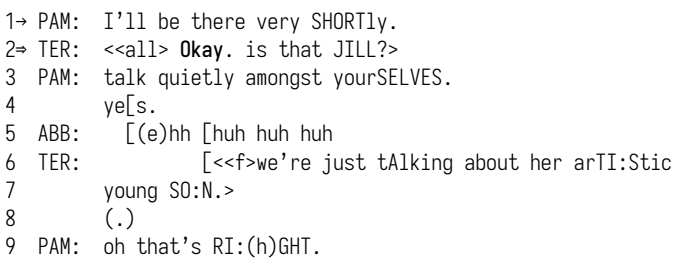

(16) "Clean up" (Camp Reunion 1_5.23) [Newer data] ((Lauren has just brought in snacks for her guests. She addresses line 1 to her sister Sally and then instructs her daughter Maggie what to do in her absence. Overlapping talk due to a floor split has been removed.))

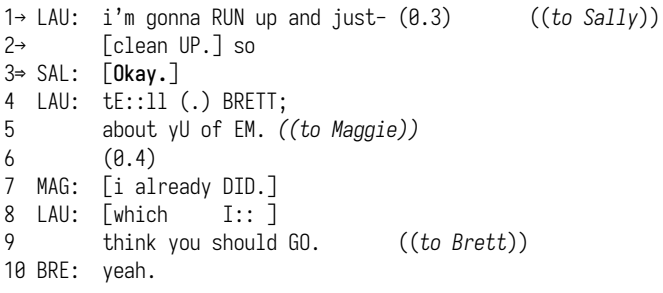

In each of these cases, the information that the interlocutor has volunteered has implications for the recipient or recipients. ${ }^{8}$ By responding with OKAY the recipient at once acknowledges the information and accepts the consequences it

8. Because these implications concern future actions that the recipients should undertake, the informings could be said to have deontic overtones, thus providing a possible clue as to how the consequential use of OKAY may have developed. 
implies. In (14), for instance, when Jill2 informs her guest Jill I'm gonna go over there (line 6), Jill responds with OKAY and then orients to its implication by promising I'll come over (line 10). In (15) and (16), the informings are accompanied by indications that they have consequences for the recipients: In (15) after the informing, Pam goes on to instruct her friends to continue talking among themselves while waiting for her to return (line 3), and in (16) Lauren announces that her informing has consequences by appending so (line 2). It emerges that she wants Maggie to tell Maggie's young cousin Brett about the University of Michigan while she (Lauren) is away (lines 4-5). If the recipients of the informings in (14)-(16) had responded not with OKAY but instead with $\mathrm{OH}$, they would have receipted the information as having led them from a $[\mathrm{K}-]$ to a $[\mathrm{K}+]$ state, but they would not have acknowledged that this change of state has consequences for their own agenda. OKAY and $\mathrm{OH}$ are thus not interchangeable as response particles in these contexts.

Now consider a selection of epistemic sequences from the newer data in which the informing is question-elicited and responded to with OKAY:

(17) "Susan Werner" (Call Friend 4984, 1138.810) [Newer data]

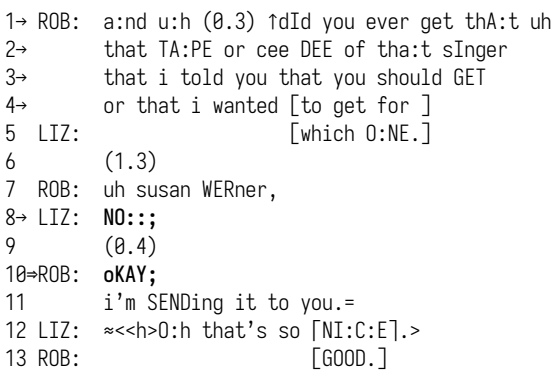

(18) "Spending the night" (Call Friend 6899, 1665.397) [Newer data]

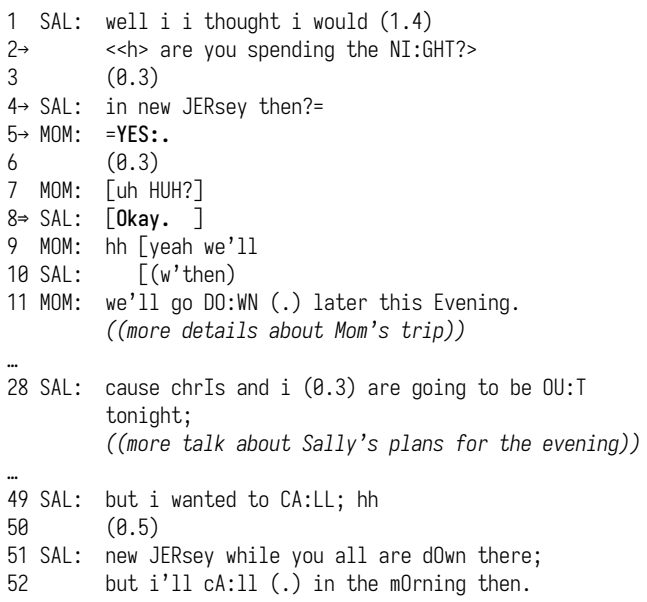


Here too the information provided in response to an interlocutor's question is followed by OKAY: in (17), Liz informs Roberta that she did not get a tape of the singer Susan Werner, whereupon Roberta produces OKAY and announces that she will send her one. In (18), Mom informs Sally that she will be spending the night in New Jersey (line 5), and Sally responds with OKAY (line 8). As it later emerges, Sally plans to call Mom while she is in New Jersey (lines 49 \& 51) but will not be able to do so that evening (line 28). The information that Mom will be spending the night in New Jersey implies that Sally can reach her there the next morning (line 52). In neither (17) nor (18) is OKAY interchangeable with a simple $\mathrm{OH}$ response: $\mathrm{OH}$ would register that the recipient now knows something they did not know before but would not acknowledge that the informing has implications for what they plan to do next.

\subsubsection{Revised-understanding $O K A Y$}

In a further set of cases comprising almost one-fourth of the epistemic OKAY tokens in the newer data, we find sequences similar to the one in Extract (13) above: The recipient uses OKAY, often together with $\mathrm{OH}$, to acknowledge a counter-informing or other-correction. Here is a sampling of such cases: (a single arrow marks the initial claim and, together with bolding, the counter-informing or other-correction; a double arrow marks the response)

(19) "A book" (Call Friend 4175, 1622.85) [Newer data]

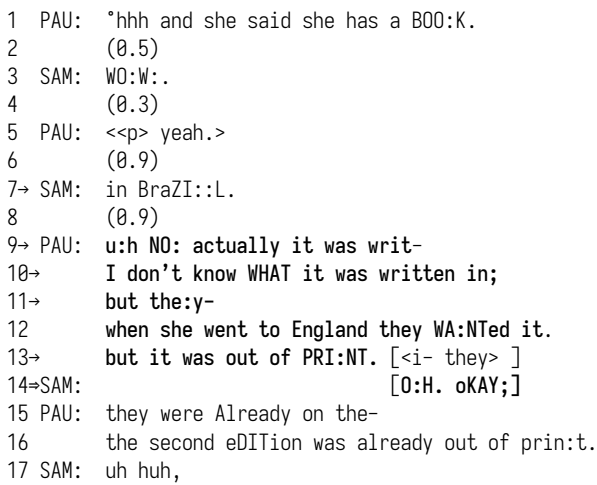

(20) "Out of touch" (Call Home 4247, 419.117) [Newer data]

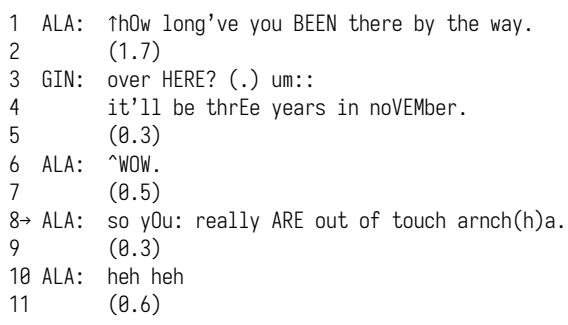




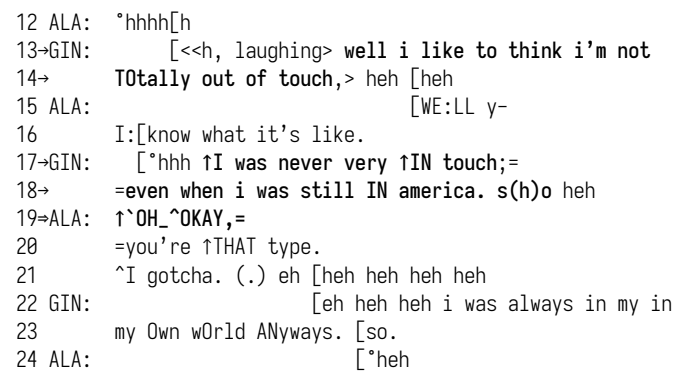

(21) "Myself and Guss" (Call Home 4074, 145.15) [Newer data]

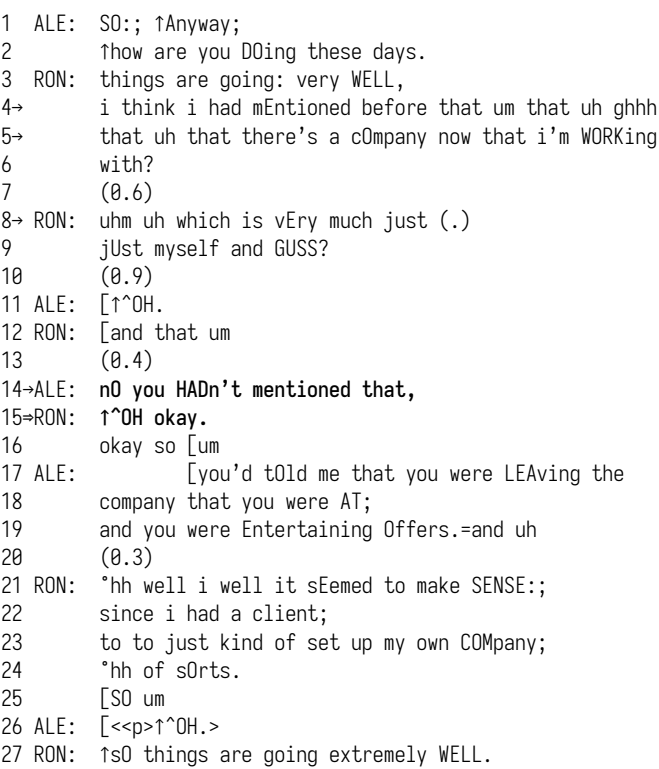

In these cases, the counter-informing or correction comes after an interlocutor has proffered a candidate understanding, as in (19), or a request for confirmation, as in (20) and (21). In both (19) and (20), the counter-informer provides 'reconciliatory information' that allows the interlocutors to resolve the incompatibility of their positions (Robinson 2009). In all three instances the recipient of the counter-informing/correction first receipts it with $\mathrm{OH}$ as something they did not know before, and then acknowledges with OKAY that it means they must revise their understanding of the situation. In (19), after OH OKAY (line 14), Sam ceases to pursue the assumption that the woman in question has written a book in Brazil, while in (20), after OH OKAY (line 19), Alan formulates his new understanding as you're THAT type (line 20). In (21), after OH OKAY (line 15), Ron proceeds to act on the revised understanding that Alec does not know about his new company by explaining how it came about (lines 21-24). In all of these cases, $\mathrm{OH}$ receipts 
the informing or correction as having brought about a change of state and OKAY marks that the recipient now accepts what that implies. ${ }^{9}$

Yet there are also cases in the newer data where following counter-informings and other-corrections OKAY is attested as a response without a preceding $\mathrm{OH}$. This is what happens in the following sequences:

(22) "Boston Jewish Film Festival" (Call Friend 6239, 542.100) [Newer data] ((Debbie is a screen writer.))

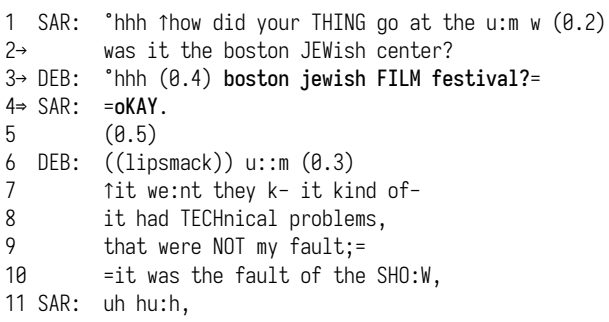

(23) "Bridesmaids" (Call Friend 6938, 1399.810) [Newer data] ((Renate is telling Anabel about the upcoming wedding of a mutual friend, which, however, will not take place that summer.))

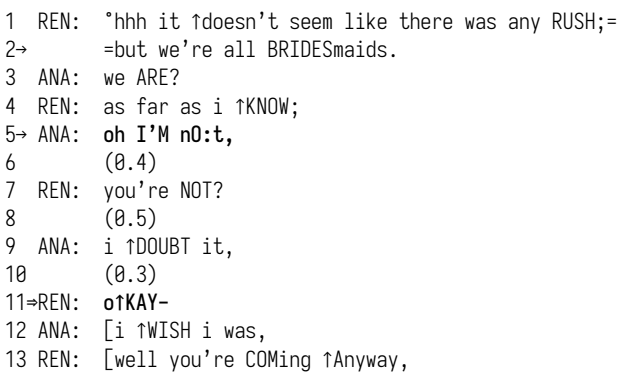

(24) "College tuition" (Call Home 4544, 1246) [Newer data]

((Two middle-aged friends are talking about what tuition was like when they went to college.))

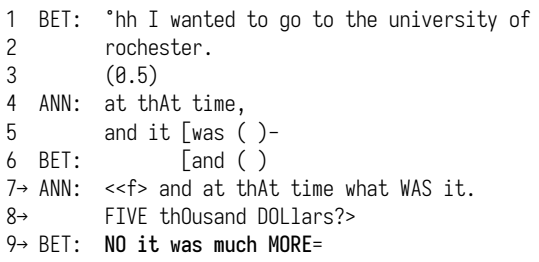

9. Of course, like all sequence-closing thirds, OKAY in these revised-understanding sequences, is also signaling 'readiness to move on to next-positioned matters' (Beach 1993). However, note that in a number of these cases (e.g., (20) and (21) here) OKAY is throughproduced with $\mathrm{OH}$, suggesting that it is the particle combination as a unit that indicating revised understanding and possible sequence closure (see also Couper-Kuhlen, In press-b). 
$10 \rightarrow \quad=$ it was like (0.5) TWELVE thousand dollars.

11 $\Rightarrow$ ANN: $\quad$ LOTKAY-

12 BET: it was like unbeLIEVable.

In these sequences the other-correction, as in (22), or the counter-informing, as in (23) and (24), is acknowledged only with OKAY in next turn, that is, it is marked as having implications that lead the recipient to a revised understanding. But the response does not include $\mathrm{OH}$ : The prior turn is not receipted as news that has led to a change of state in the recipient's knowledge. This may be because in (22) Sarah's try at the name of the festival is not far off the mark anyway; in (23) because Renate's reiterated query in line 7 suggests disbelief; ${ }^{10}$ and in (24) because Ann has already implied a belief that the cost of tuition was extremely high. In other words, in (22)-(24) the speakers are not making a big deal out of the corrections and counter-informings and what they imply for their beliefs or knowledge.

From a comparison of (19)-(21) and (22)-(24), we can conclude that it matters whether the response to a counter-informing includes $\mathrm{OH}$ or not. This is an indication that the tokens $\mathrm{OH}$ and $\mathrm{OKAY}$ are not interchangeable with one another following counter-informings and other-corrections: Each makes a distinct contribution to the response and the way it deals with the prior informing.

So far, we have seen that almost three-quarters of the epistemic OKAY tokens in the newer data are used as in Extracts (12) and (13) from the older data. These consequential and revised-understanding OKAYs are not interchangeable with $\mathrm{OH}$ as responses to informings and counter-informings: They have distinct work to do. Moreover, the uses are not new; they simply occur much more frequently in the newer data collection.

Yet there is a third kind of OKAY accounting for more than a quarter of the tokens in epistemic sequences in the newer data, which we refer to as nonconsequential OKAY. This is a novel use, one not documented in the older data, and it is a major contributor to the remarkable rise of epistemic OKAY.

\subsubsection{Non-consequential OKAY}

In numerous sequences in the newer data, OKAY appears as a response to an informing that is neither consequential for the recipient's agenda, as in (12) above, nor corrective of the recipient's claims or expressed beliefs, as in (13). In these sequences, there are no implications deriving from the informing that might be relevant for the recipient; instead, OKAY appears to receipt the information much as $\mathrm{OH}$ would do. Here is a sampling of sequences in which such an informing

10. As Heritage (1984) points out, the production of $\mathrm{OH}$ after a counter-informing typically implicates the speaker's acceptance of the information as fact. In the context of contested information it may be avoided for precisely this reason (p. 339, n12). 
is question-elicited: (a single arrow marks the question and the answer, which is bolded; a double arrow marks the response)

(25) "Weight Watchers" (Farmhouse, 19.56) [Newer data] ((Mom and Laura have been telling Donna about Weight Watchers and the recommendations their adviser gives them there.))

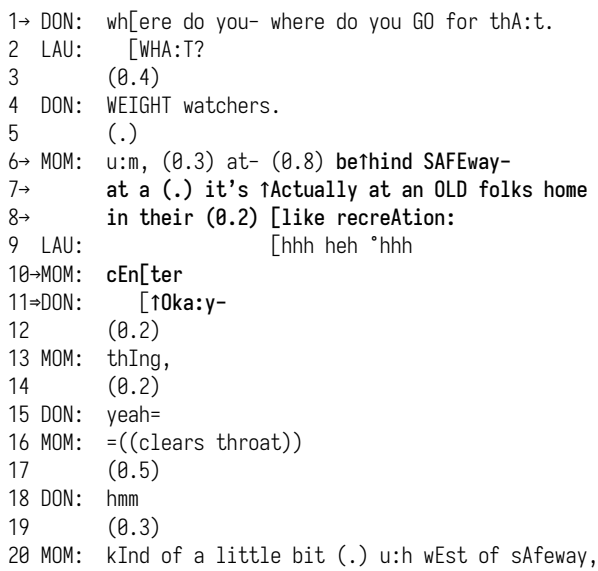

There is no evidence in this conversation that the location of Weight Watchers is consequential for Donna (she herself is athletic and jogs to keep in shape), nor is it correcting a prior understanding of hers. But Donna receipts it with OKAY (line 11). In this context it would have been just as appropriate for Donna to respond with $\mathrm{OH}$ : in other words, there is little difference between what this OKAY does and what $\mathrm{OH}$ would do here.

(26) “Bell Northern Research" (Call Friend 4175, 278.249) [Newer data] ((Paul is describing to Sam his new job in interface design with Bell Corp.))

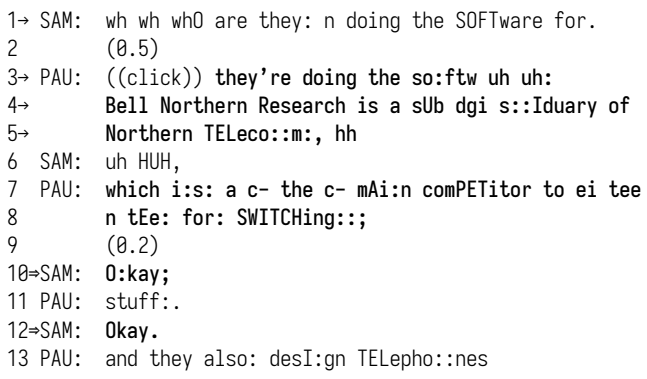

The information about who Paul's company provides the software for (lines 3-5 and 7-8) has no consequences for Sam nor does it counter anything he has claimed, but it is receipted with OKAY in line 10 and, after an increment, again in line 12. Here, too, Sam could easily have responded with $\mathrm{OH}$. 
(27) "Scheduling" (Call Friend 6239: 1662.625) [Newer data]

((Debbie, a screen writer, has just declared that she does not want her temp job to become full-time.))

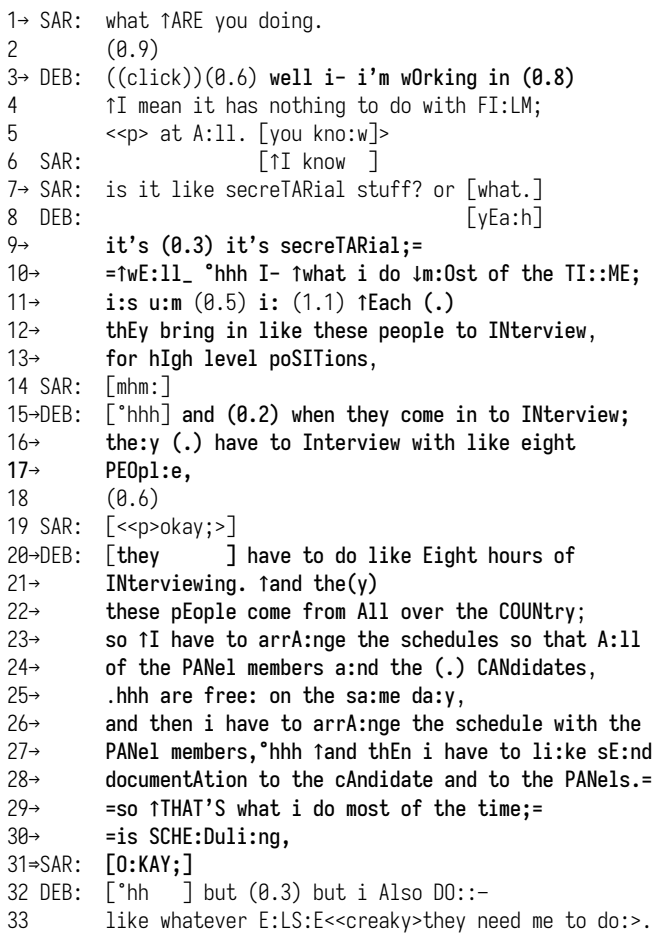

The detailed information that Debbie provides in response to Sarah's queries, culminating in the answer that she does scheduling, is not relevant in any way to Sarah's future actions nor does it not counter or correct any claim Sarah has made. And yet at line 31, when Debbie's telling has reached a point of possible completion, Sarah receipts it with OKAY. ${ }^{11}$ In this extract as well as in (25) and (26), the particle OKAY appears to be functioning much like a sequence-closing $\mathrm{OH}$ : It is proposing that the information sought has been provided and the sequence can now be brought to a close (Schegloff 2007: 119).

Non-consequential OKAY tokens can also be found in the course of extended tellings that have not been explicitly solicited. In the following extract they are produced by the recipient when the teller reaches intermediary points in his report:

11. Note that Sarah uses another OKAY in line 19, which however, occurs at a point when the telling is pragmatically incomplete: In this case OKAY is arguably serving as a continuer. 
(28) "Multi-mode lasers" (Call Home 4074, 346.53) [Newer data] ((Alec is working on his thesis and is explaining to Ron what it is about.))

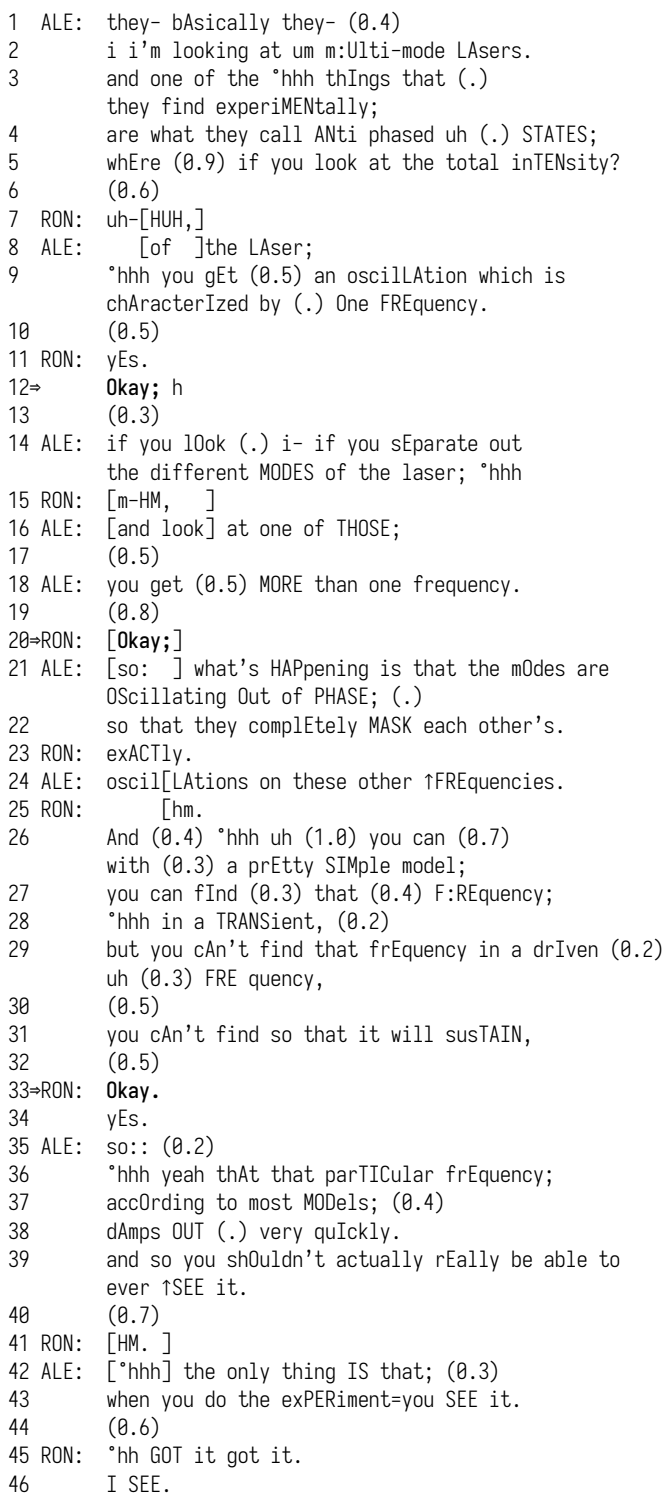

It is instructive to compare the use of OKAY here (lines 12, 20, and 33) with $u h$ $h u h$ in line 7 and $m-h m$ in line 15. The latter objects occur after if-clauses, that is, at points of syntactic incompletion, and with slightly rising final pitch they serve as standard continuers (Schegloff 1988). The three OKAY tokens, however, occur at points of possible syntactic completion and have final falling pitch; in two cases 
they co-occur with yes. As in (25)-(27), the OKAY tokens in (28) mark points of possible completion, but they are intermediary points within the larger telling. ${ }^{12}$

As with other non-consequential OKAYs, there is no sense in which the information that Ron is imparting to Alec in (28) has implications for Alec's future actions, nor does it counter any contrary opinion or belief Alec has expressed. Yet it is less clear whether $\mathrm{OH}$ would be an appropriate substitute: This may be because the telling is pragmatically incomplete at each intermediary point. In this sense the OKAY tokens in (28) play a role that is somewhere in between that of classic continuers such as UH-HUH and M-HM and sequence-closing thirds such as $\mathrm{OH}{ }^{13}$

\subsection{Factors contributing to the rise of epistemic OKAY}

To summarize our findings so far: We have identified three distinct uses of OKAY in informing and counter-informing sequences in the newer data: consequential, revised-understanding, and non-consequential. The first two of these are also attested, if much less frequently, in the older data: see Table 3.

Table 3. Types of epistemic OKAY in the two data sets

\begin{tabular}{lcccc}
\hline & Consequential & $\begin{array}{c}\text { Revised } \\
\text { understanding }\end{array}$ & $\begin{array}{c}\text { Non- } \\
\text { consequential }\end{array}$ & $\begin{array}{c}\text { Total epistemic } \\
\text { OKAYs }\end{array}$ \\
\hline Older data & $10(53 \%)$ & $9(47 \%)$ & - & 19 \\
Newer data & $69(49 \%)$ & $32(23 \%)$ & $39(28 \%)$ & 140 \\
\hline
\end{tabular}

Yet in contrast to consequential and revised-understanding uses, which are documented in both sub-collections, the non-consequential use of OKAY is an innovation in the newer data. In the 1960s, recipients of informings, especially question-elicited ones, do not produce OKAY after the information has been provided unless it is in some way consequential for their own actions or corrective of their beliefs or understanding.

There are thus two factors that can be held accountable for the remarkable rise of epistemic OKAY in the newer data: (i) OKAY is used significantly more

12. Guthrie (1997), who examines academic advising sessions, also finds $m m h m m$ being used as a continuer at points in an interlocutor's talk that are syntactically, intonationally and/or pragmatically incomplete, while okay is used as an acknowledgment token after utterances which are in some sense complete.

13. One anonymous reviewer suggested that there may be a parallel here with the use of Right in Australian and British English to mark epistemic dependency between two units of talk within a complex activity such as an extended informing (Gardner 2007). 
often after informings that have implications for the recipient's agenda and/or lead to a revised understanding of the matter at hand ( 19 tokens, or $7 \%$ of the 277 OKAYs in the older set vs. 101 tokens, or $37 \%$ of the 273 OKAYs in the newer set), and (ii) OKAY is now used to respond to informings that are not in any way consequential for the recipient's agenda or beliefs and expectations (39 tokens, or 14\% of the 273 OKAYs in the newer set vs. o tokens out of 277 OKAYs in the older set).

\section{Discussion}

In the foregoing section, we explored the rise of epistemic OKAY in the newer data and documented its uses at some length. Two questions now arise in conjunction with these findings.

\subsection{Consequential and corrective informings in the older data}

A first question concerns the large increase in consequential and corrective OKAYs in the newer data. Are there simply more consequential and corrective informings being made in the 1990s and early 200os, or is OKAY gradually expanding its domain in epistemic sequences? Are consequential and corrective informings also responded to with $\mathrm{OH}$ in the older data?

The design of this study does not lend itself to a thorough exploration of this question, but there is some preliminary evidence to suggest that in the older data $\mathrm{OH}$ is also used to receipt question-elicited news with consequences for the speaker. Consider, for instance, the following exchange, which takes place at the beginning of a phone call by Margy to her friend Emma:

(29) “Call out some numbers” (NB 27, 1.497) [Older data]

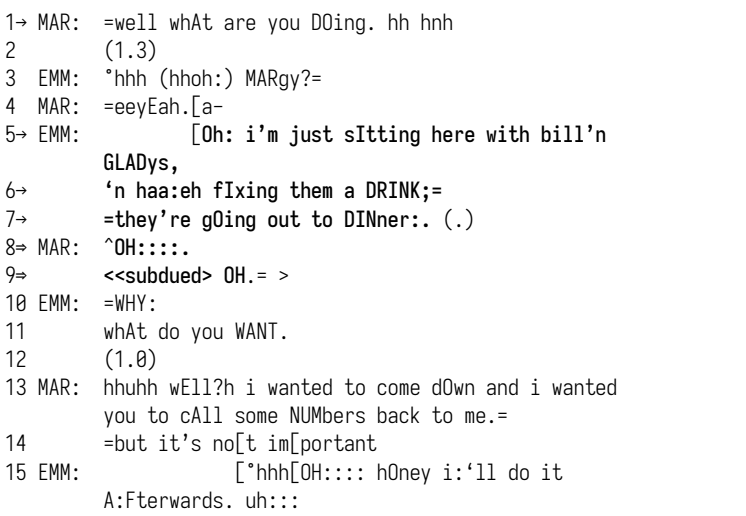


Emma's informing that she is having drinks with Bill and Gladys (lines 5-6) is consequential for Margy: She (Margy) helps out with accounting in her husband's firm and, as she later explains, she has called to enlist Emma's help with calling back some numbers. In response to Emma's informing that she has company and thus is otherwise occupied, Margy produces two prosodically modified tokens of $\mathrm{OH}$ (lines 9 and 10): the first, with its high rising-falling pitch contour, suggestive of surprise (Reber 2012), the second, with its 'subdued' prosody, suggestive of disappointment (Couper-Kuhlen 2009). This affect display is presumably what leads Emma to now ask what Margy had in mind (lines 10-11).

$\mathrm{OH}$ is also attested numerous times in the older data as a response to othercorrections and counter-informings. Here are two instances where this happens:

(30) "Ravioli" (Chicken Dinner, 13.14) [Older data]

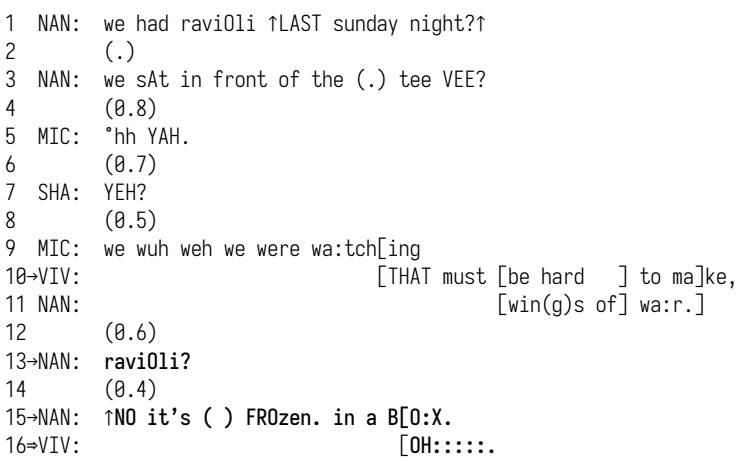

In line 15 Nancy corrects Vivian's assumption that ravioli is hard to make (line 10) by explaining that what she prepared was frozen and in a box, whereupon Vivian responds with a lengthened $\mathrm{OH}$ (line 16).

(31) "Personal phone calls" (Chicken Dinner, 19.50) [Older data]

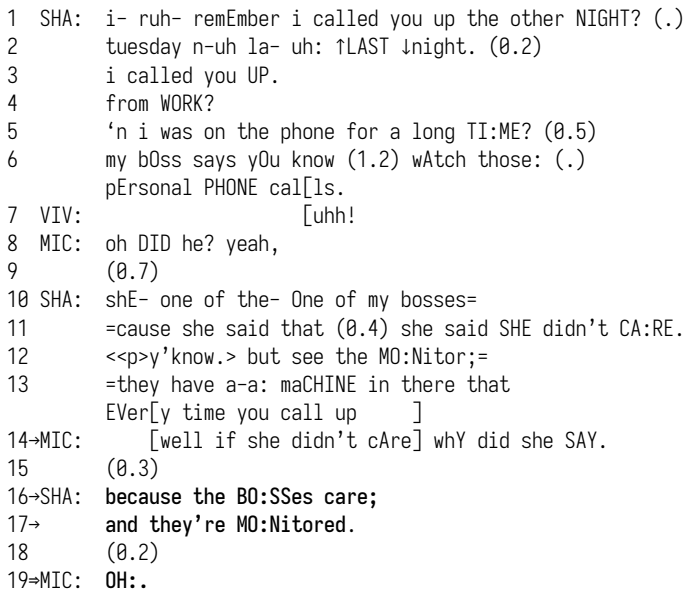




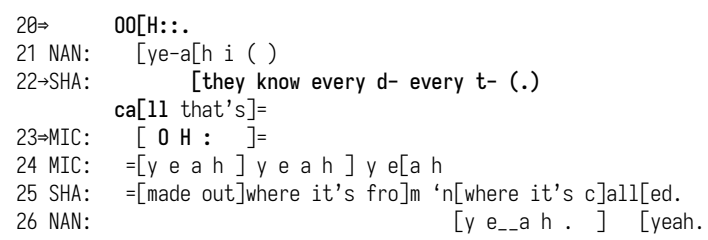

In line 14, Michael implies that if one of Shane's bosses claims not to care about his personal phone calls, there is no justification for her telling him to keep them to a minimum. But Shane corrects this assumption by explaining that other bosses care and that his phone calls are monitored by a machine (lines 16-17). Michael receipts and acknowledges Shane's correction with two tokens of $\mathrm{OH}$ in lines 19-20 and another, following further reconciliatory information, in line 23.

Based on examples such as these, we can provisionally conclude that in the older data it is primarily $\mathrm{OH}$ that is used to receipt consequential informings and corrections/counter-informings. Since OKAY is only attested occasionally in these environments, it would appear that epistemic OKAY in the newer data is encroaching on territory where $\mathrm{OH}$ was used before.

\section{2 $\mathrm{OH}$ as a news receipt in the newer data}

A second question arising from our findings concerns the role of $\mathrm{OH}$ in the newer data. Does the new, non-consequential use of OKAY, which we have argued is interchangeable with $\mathrm{OH}$, mean that $\mathrm{OH}$ has been replaced as a news receipt in the newer data? In other words, is the particle $\mathrm{OH}$ still found at all after informings and counter-informings in the newer data? If so, under what circumstances?

Here too, because the present study has focused on OKAY and not $\mathrm{OH}$, we cannot answer this question conclusively. However, it is revealing that a number of the epistemic sequences we have encountered with OKAY also feature instances of $\mathrm{OH}$ after informings and counter-informings. For example, in Extract (21) above, $\mathrm{OH}$ occurs in line 11 as a response to the news that Ron is working for a company involving just himself and Guss, and in line 26 it is used again in response to the unsolicited information that Ron has set up this company for himself. Both these $\mathrm{OH}$ tokens have a high, 'pointed' pitch peak, which has been associated in informing sequences with displays of surprise (Reber 2012).

There are also cases in the newer data where $\mathrm{OH}$ is used to receipt an othercorrection. For instance:

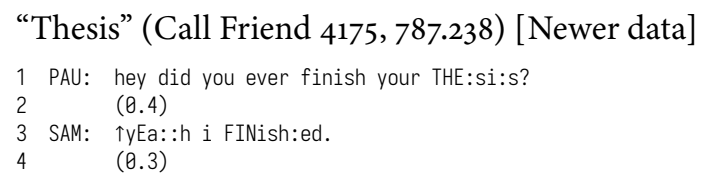




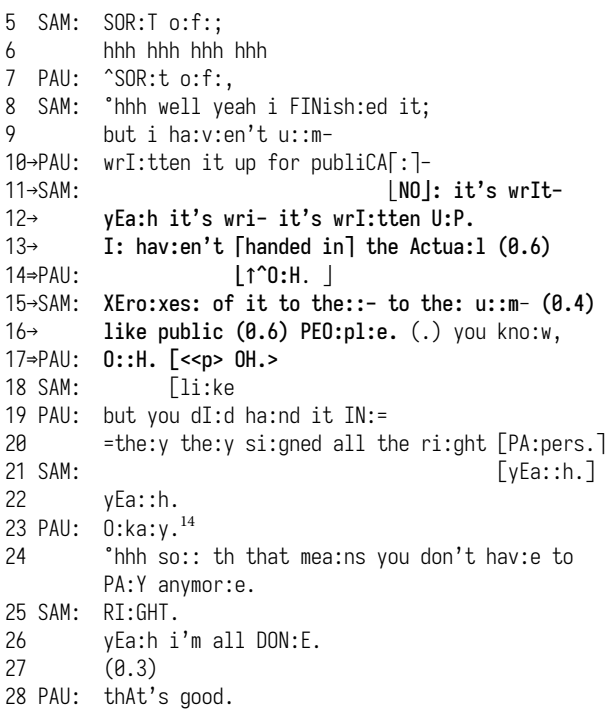

When Sam adds sort of (line 5) to the report that his thesis is finished, he hints that there is something that he has not yet done, which he begins to formulate with but I haven't um (line 9). Paul now provides a candidate turn completion: written it up for publica(tion) (line 10). However, Sam counters with no it's written up (lines 11-12) but explains I haven't handed in the actual xeroxes of it to the public people (lines 13, 15-16). Paul responds to each of these informings with an affectladen $\mathrm{OH}$ token. His first $\mathrm{OH}$ (line 14) is done, in overlap, with an extra high, 'pointed' pitch peak indicative of surprise (Reber 2012). His second OH (line 17), produced in the clear, falls from high to mid and is lengthened, conveying approximately 'NOW I understand' (cf. Koivisto 2015). ${ }^{15}$ It is immediately followed by another token of $\mathrm{OH}$ produced with soft volume.

These OHs, like the ones in Extract (21), are delivered with marked prosody and make affective displays, here of surprise and 'now-understanding', respectively. It is still an open question whether OKAY can be used to display similar types of affect and if so, what kind of prosodic marking would be needed to do so. ${ }^{16}$ Nevertheless, it could be cautiously hypothesized that in the newer data $\mathrm{OH}$

14. Note this non-consequential use of OKAY to respond to an informing elicited by Paul's requests for confirmation in lines 19-20.

15. The contour used here is akin to the one described by Reber as displaying 'slow realization' (2012:106).

16. Beach (2020) considers some affect-laden displays brought about by prosodically marked OKAYs, but surprise and now-understanding are not among them. 
may be preferred over OKAY as an epistemic response particle when affective stances such as surprise and now-understanding are to be displayed.

The following extract suggests that empathy may be another affect display preferably accomplished with $\mathrm{OH}$ in epistemic sequences:

(33) "Unfortunate" (Farmhouse, 1009.04) [Newer data]

((Mom and Laura have been telling Michelle and Donna about the surprise birthday party they organized for Dad. The guests arrived as he was out in the field tending to a prolapsed cow.))

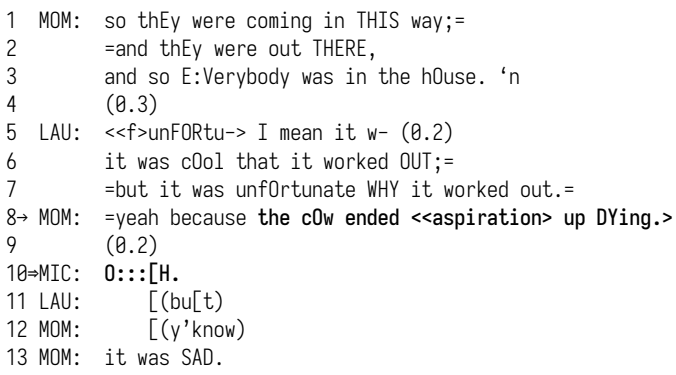

The news that the prolapsed cow died is part of the extended telling that Mom and Laura have been delivering to Michelle and Donna but it is one that calls for a special affective response. In Heritage's words this detail creates an empathic moment (2011). Michelle responds not with OKAY but with a breathy, drawn-out, downwards gliding $\mathrm{OH}$, which, in the given context, serves as a display of strong empathy. It is an open question whether the same effect could be achieved with OKAY. It could nevertheless be speculated that a division of labor may be developing in the newer data whereby $\mathrm{OH}$ is preferred on occasions when the response to an informing or counter-informing calls for a marked display of affect such as surprise, now-understanding, or empathy, but that OKAY - whether prosodically unmarked or marked - is a choice elsewhere. Clearly, more work is needed in the future to investigate this.

\subsection{Possibility spaces in informing and counter-informing sequences}

A hypothesis like the one above can only be supported empirically if we examine responsive slots in epistemic sequences more generally. For instance, in the case of an unsolicited informing with the following structure:

(34) Unsolicited informing sequence

1 A: Informing or telling

$2 \rightarrow \mathrm{B}$ : Response 
we must ask, what options does B have for responding in second position? And what affective stances can be relevantly displayed with each one? Similarly, in the case of a solicited informing or of a counter-informing:

(35) Question-elicited informing sequence

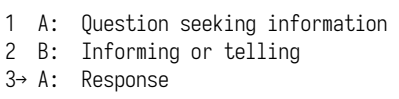

(36) Counter-informing sequence

$\begin{array}{ll}1 & \text { A: } \\ 2 & \text { B: Countem-informing } \\ 3 \rightarrow & \text { A: Response }\end{array}$

we must ask: What options does A have for responding in third position and what affective stances can be relevantly displayed with each one? As Stivers (2018) has put it, structural slots such as the arrowed ones in (34)-(36) create 'possibility spaces' where speakers choose among options for responding. Together the set of options form a 'paradigm' for responding to informings and counter-informings. In this paper we have examined only one response option in the informingresponse paradigm, namely the particle OKAY, although we have contrasted it on occasion with freestanding $\mathrm{OH}$. Needless to say, there are many other options and option types for responses in informing sequences, including the particles $m m-h m$, uh-huh, yeah, (al)right, and combinations thereof as well as phrasal and clausal forms (Thompson et al. 2015 discuss some of these). A future project large-scale - would be required to explore the differences that each single choice in the informing-response paradigm has for the sequence and what this choice implies sequentially and interactionally for subsequent talk.

\section{Conclusion: Interactional Linguistics and language over time}

We began with a comparison of the particle OKAY in two sets of American English conversational data, one from the 1960 s and the other, a generation later, from the 1990 s and early 20oos. The comparison revealed differences in the use of OKAY - skewed frequencies and new uses - that could be only partially accounted for by the nature of the conversations involved. The most striking difference, the rise of epistemic OKAY, became the focus of this investigation, which aimed to explore how and why OKAY has increased so dramatically in frequency over the last few decades.

A first step involved determining how epistemic sequences, built around informings and extended tellings, were managed in the older data. Much as Heritage's (1984) study documented, it is primarily $\mathrm{OH}$ that is used to receipt such 
informings there. In our older data set OKAY responses are rare in these environments: Only 19 tokens of epistemic OKAY were identified in approximately seven hours of conversation. These OKAY tokens were used in two distinct ways: (i) to acknowledge information that is consequential for the speaker's future project or agenda, and (ii) (often together with $\mathrm{OH}$ ) to acknowledge information that counters or corrects the speaker's prior claims or expressed beliefs.

These same two uses of epistemic OKAY are documented in the newer data collection as well, although they are significantly more frequent there. Since $\mathrm{OH}$ is also found following consequential and corrective information in the older data, it was provisionally concluded that OKAY is expanding its domain over $\mathrm{OH}$ in the newer data and is being used more and more as a response to these two types of information.

But also a third, new use of OKAY appears in the newer data, namely nonconsequential OKAY, deployed to receipt information that is neither consequential for the speaker nor corrective of their beliefs in any way. Since this use comprises more than a quarter of all epistemic OKAY tokens in the newer data, it can be seen as a major contributor to the rise of epistemic OKAY. Yet OKAY has not fully replaced $\mathrm{OH}$ as a news receipt in the newer data. Instead, instances of $\mathrm{OH}$ are still found when an affect-laden response displaying surprise, nowunderstanding, or empathy is called for. A division of labor between OKAY and $\mathrm{OH}$ may be establishing itself in the newer data for the receipt of nonconsequential information.

In conclusion, by revealing changes in the use of epistemic OKAY over the course of forty years, this study has shown that changes in the conversational use of language are ongoing and that we can investigate them with the tools of Interactional Linguistics. The procedure involves comparing and contrasting possibility spaces created by the structural slots of specific types of conversational sequences in two or more data sets from different periods in time. As we have shown, both the options in such possibility spaces and their relative frequencies can undergo change over time, allowing us to view language use longitudinally. ${ }^{17}$

\section{Acknowledgements}

I am grateful to two anonymous reviewers and the editors of Interactional Linguistics for their penetrating comments on an earlier version of this paper. All remaining errors and misjudgments are my own.

17. For general longitudinal studies of social interaction, see Pekarek Doehler, Wagner, and González-Martinez, Eds. (2018). 


\section{References}

Beach, W.A. (1993). Transitional regularities for 'casual' "Okay" usages. Journal of Pragmatics, 19, 325-352. https://doi.org/10.1016/0378-2166(93)90092-4

Beach, W.A. (2020). Using prosodically marked "Okays" to display epistemic stances and incongruous actions. Journal of Pragmatics, 169, 151-164. https://doi.org/10.1016/j.pragma.2020.08.019

Betz, E., A. Deppermann, L. Mondada, \& M.-L. Sorjonen, Eds. (In press). OKAY across languages: Toward a comparative approach to its use in talk-in-interaction. Amsterdam: John Benjamins. https://doi.org/10.1075/slsi.34

Clayman, S. and J. Heritage. (2002). The News Interview: Journalists and Public Figures on the Air. Cambridge: Cambridge University Press. https://doi.org/10.1017/CBO9780511613623

Couper-Kuhlen, E. (2009). A sequential approach to affect: The case of 'disappointment'. In M. Haakana, M. Laakso and J. Lindström (Eds.), Talk in Interaction. Comparative dimensions (pp. 94-123). Helsinki, Finnish Literature Society.

Couper-Kuhlen, E. (2014). What does grammar tell us about action? Pragmatics, 24(3), 623-647. https://doi.org/10.1075/prag.24.3.08cou

Couper-Kuhlen, E. (In press-a). The prosody and phonetics of OKAY in American English. In E. Betz, A. Deppermann, L. Mondada \& M.-L. Sorjonen (Eds.), OKAY across languages: Toward a comparative approach to its use in talk-in-interaction. Amsterdam: John Benjamins. https://doi.org/10.1075/slsi.34.05cou

Couper-Kuhlen, E. (In press-b). OH+OKAY in informing sequences: On fuzzy boundaries in a particle combination. Open Linguistics. Special issue "Weak cesuras: What fuzzy boundaries can accomplish in talk-in-interaction”, D. Barth-Weingarten \& R. Ogden (Eds.).

Couper-Kuhlen, E. \& D. Barth-Weingarten. (2011). A system for transcribing talk-ininteraction: GAT 2. English translation and adaptation of Selting, M. et al.: Gesprächsanalytisches Transkriptionssystem 2. Gesprächsforschung Online, 12, 1-51.

Couper-Kuhlen, E. \& M. Selting (Eds.) (2001). Studies in Interactional Linguistics. Amsterdam: John Benjamins. https://doi.org/10.1075/sidag.10

Drew, P. (2012). What drives sequences? Research on Language and Social Interaction, 45(1), 61-68. https://doi.org/10.1080/08351813.2012.646688

Gardner, R. (2007). The 'Right 'connections: Acknowledging epistemic progression in talk. Language in Society, 36, 319-341. https://doi.org/10.1017/So047404507070169

Guthrie, A.M. (1997). On the systematic deployment of OKAY and MMHMM in academic advising sessions. Pragmatics, 7, 397-415. https://doi.org/10.1075/prag.7.3.06gut

Heritage, J. (1984). A change-of-state token and aspects of its sequential placement. In J.M. Atkinson \& J. Heritage (Eds.), Structures of social action. Studies in Conversation Analysis (pp. 299-345). Cambridge England: Cambridge University Press.

Heritage, J. (2011). Territories of knowledge, territories of experience: Empathic moments in interaction. In T. Stivers, L. Mondada \& J. Steensig (Eds.), The morality of knowledge in conversation (pp. 159-183). Cambridge: Cambridge University Press. https://doi.org/10.1017/CBO9780511921674.008

Heritage, J. (2012a). Epistemics in action: Action formation and territories of knowledge. Research on Language and Social Interaction, 45(1), 1-29. https://doi.org/10.1080/08351813.2012.646684 
Heritage, J. (2012b). The epistemic engine: Sequence organization and territories of knowledge. Research on Language and Social Interaction, 45(1), 30-52. https://doi.org/10.1080/08351813.2012.646685

Koivisto, A. (2015). Displaying now-understanding: The Finnish change-of-state token 'aa'. Discourse Processes, 52(2), 111-148. https://doi.org/10.1080/0163853X.2014.914357

Lerner, G.H., Ed. (2004). Conversation Analysis: Studies from the first generation. Amsterdam: John Benjamins. https://doi.org/10.1075/pbns.125

Maynard, D. (1997). The news delivery sequence: Bad news and good news in conversational interaction. Research on Language and Social Interaction, 30, 93-130.

Metcalf, A. (2010). OK: The improbable story of America's greatest word. New York: Oxford University Press.

Ochs, E., E.A. Schegloff, \& S.A. Thompson (Eds.) (1996). Interaction and grammar. Cambridge: Cambridge University Press. https://doi.org/10.1017/CBO9780511620874

Pekarek Doehler, S., J. Wagner, \& E. González-Martinez (Eds.) (2018). Longitudinal studies on the organization of social interaction. London: Palgrave Macmillan. https://doi.org/10.1057/978-1-137-57007-9

Robinson, J.D. (2009). Managing counterinformings: An interactional practice for soliciting information that facilitates reconciliation of speakers' incompatible positions. Human Communication Research, 35, 561-587. https://doi.org/10.1111/j.1468-2958.2009.01363.x

Sacks, H. (1992). Lectures on conversation, Volumes I \& II. Oxford, UK/Cambridge, USA: Blackwell.

Sacks, H., E. Schegloff, \& G. Jefferson. (1974). A simplest systematics for the organization of turn-taking for conversation. Language, 50, 696-735. https://doi.org/10.1353/lan.1974.0010

Schegloff, E. (1982). Discourse as an interactional achievement: Some uses of "uh huh" and other things that come between sentences. In: D. Tannen, Ed., Analyzing discourse: Text and talk (pp. 71-93). Washington, DC: Georgetown University Press.

Schegloff, E. (1988). Presequences and indirection: Applying Speech Act Theory to ordinary conversation. Journal of Pragmatics, 12, 55-62. https://doi.org/10.1016/0378-2166(88)90019-7

Schegloff, E.A. (2007). Sequence organization in interaction: A Primer in Conversation Analysis, Vol. 1. Cambridge: Cambridge University Press. https://doi.org/10.1017/CBO9780511791208

Schegloff, E.A. \& H. Sacks. (1973). Opening up closings. Semiotica, 7, 289-327.

Selting, M., P. Auer, D. Barth-Weingarten, et al. (2009). Gesprächsanalytisches Transkriptionssystem 2. Gesprächsforschung Online, 10: 353-402.

Stevanovic, M. \& A. Peräkylä. (2012). Deontic authority in interaction. The right to announce, propose, and decide. Research on Language and Social Interaction, 45(3), 297-321. https://doi.org/10.1080/08351813.2012.699260

Stivers, T. (2018). How we manage social relationships through answers to questions: The case of interjections. Discourse Processes, 56(3), 191-209. https://doi.org/10.1080/0163853X.2018.1441214

Terasaki, A. K. (2004). Pre-announcement sequences in conversation. In: G.H. Lerner (Ed.), Conversation Analysis: Studies from the first generation (pp. 171-223). Amsterdam: Benjamins. https://doi.org/10.1075/pbns.125.11ter

Thompson, S.A., B. Fox, \& E. Couper-Kuhlen. (2015). Grammar in everyday talk: Building responsive actions. Cambridge: Cambridge University Press.

https://doi.org/10.1017/CBO9781139381154 


\section{Address for correspondence}

Elizabeth Couper-Kuhlen

Bogotastr. 4, 14163 Berlin

Germany

elizabeth.couper-kuhlen@helsinki.fi

(D) https://orcid.org/oooo-0003-2030-6018

\section{Publication history}

Date received: 10 July 2020

Date accepted: 3 February 2021

Published online: 16 April 2021 